\title{
Wnuironmental Conservation
}

\author{
INSTRUCTIONS FOR AUTHORS
}

\begin{abstract}
'Manuscripts' must be original, in clear English, and not currently under consideration for publication elsewhere. Three copies should be submitted - including 1 or 2 on light airmail paper — in double-spaced typing on one side only of consecutively numbered pages of uniform size not more than $30 \mathrm{~cm}$ in length, leaving adequate margins. Survey and research papers should preferably be between 4,000 and 7,000 words in length and only exceed 8,000 words (including references etc.) if subsidized. Other contributions should not exceed 3,000 words and those of more than onefifth that length or two typed pages should be suitably subdivided with a brief heading to each section. Primary sub-headings in major papers should be centred, whereas any secondary ones should be brought out to the lefthand margin. Footnotes are, in general, deprecated except when inserted for editorial exposition. Headings of items for the sections 'Conferences \& Meetings' and 'Reviews \& Notices' must be in the style of the Journal the former naming the occasion, place, and dates, and the latter complete with publisher and place, preliminary and other page-spreads, then indication of any illustrations, all three dimensions in metric, price, and date of publication (which should normally be not earlier than the preceding calendar year). The optimum length in both these categories is 350-500 words, though up to double the latter may be allowed for items of outstanding importance.
\end{abstract}

Style of Writing should be direct and concise, with punctuation etc. according to The Oxford Dictionary for Writers and Editors and spellings according to the Oxford English Dictionary. Dates should be in the form " 1 March 1974' and single quotes should be used throughout (except for the use of double quotes within quotes). Any symbols or abbreviations employed should be the conventional ones, with omission of all unnecessary full stops (periods). If other than metric units are used, the metric equivalents must be inserted in parentheses after them. Submissions should be as neat and 'clean' as possible, and checked meticulously for errors and inconsistencies; always keep a fully corrected copy for reference in editorial correspondence and in case of loss of the original.

Tables may be included in the main body of the manuscript but must in all cases be numbered consecutively with roman numerals, and appropriately headed. They should be kept as simple and short as possible, though longer Appendices may exceptionally be allowed. All illustrations - whether photographs, drawings, maps (always with scales!), or graphs - are to be numbered in a single sequence as 'Fig. 1', 'Fig. 2', etc., and so referred to in the text. Each must be clearly captioned, with acknowledgement of source when necessary, the captions being typed consecutively on a separate sheet at the end of the paper.

Scientific Names of plant and animal genera, subgenera, species, and lower taxa, need to be used for precision and underlined for italic, specific and lower epithets being written with a 'small' initial letter; the initial letters of precise (but not group) English and other vernacular names should, however, be capitalized. Nomenclature should be in accordance with the appropriate international code, and the publishing authority may if desired be given the first time a name is mentioned, though in that event consistency should be maintained with other names throughout the paper. Ecological and other scientific terms should either follow reasonably standardized usage or be defined the first time they are employed in a paper-throughout which this meaning alone should be used.

With our very wide readership, verbal descriptions are much preferred to complicated formulae and equations, which should be avoided so far as possible. Acronyms, if not universally familiar, should be spelt out the first time they are used in a paper.

Submission of major 'manuscripts' should be by 15 December, 15 March, 15 June, and 15 September, for consideration for the Spring. Summer, Autumn, and Winter issues, respectively, the absolute deadlines (particularly for brief news etc. items) being 15 January, 15 April, 15 July, and 15 October. As, however, extensive 'pre-editing' and correspondence are commonly necessary before an accepted paper is ready to go for typesetting, submission should be considerably earlier - to give a reasonable chance of publication in the issue of the following season if space allows. All refereeing is strictly confidential unless a referee agrees to the release of his or her identity through the Editor, who then uses his discretion.

Titles of all papers should be as short as possible, inter alia for use as running headings. Those of research and survey papers are to be followed by the names of the Author or Authors (including preferred given name in full and any further initial or initials, and followed by indications of any higher degrees and where obtained). Thereafter comes an indication of academic or other allegiance and/or senior post or posts held and full address underlined for italic. Instead of the customary Abstract at the beginning, a SUMMARY is required at the end of each paper, to recapitulate and emphasize its main points. This should preferably not exceed about 450 words in length, in 2 or 3 paragraphs, and follow any ACKNOWLEDGEMENTS. It should be 'self-contained' in being easily understandable without reference to the general text. Short communications etc. do not need a Summary, and the 'signature' and address of their Authors should be placed at the end, after any References.

Literature References are treated according to the Harvard System with the Author (or Authors connected with an ampersand if two, or with 'et al' replacing surnames after the first if more than two), and indicating the year of publication in parentheses: e.g. '(Smith, 1973)' or 'according to Smith (1973)'. References should be cited as 'in press' (not by date) only when already accepted for publication, the journal or publisher and place being named. Whereas in short communications any references may if desired be given in parentheses in the text, normally - and always in long papers they are to be collected together in a list headed 'REFERENCES', alphabetically arranged by [first] Authors' sumames, but unnumbered, at the end of the paper. There, all Authors' names and initials are required, followed by the date of publication (in parentheses), and then the full title of the paper (with capitalization of initials only where required). There follow the title of the periodical, underlined for italic and given in full or contracted consistently, then the volume number in bold-face (with number of part, if desired, closed up in parentheses), then the page-spread in the form 'pp. 321-5', and finally an indication of 'illustr.' (if it is).

For books and other 'separate' publications, the full title is given, upholding any capitals and underlining for italic, and then the name of the publisher and place or places of publication, followed by full details of pages in the form of e.g. 'xxvii + 294 pp., illustr.' (if it is). In symposium volumes the page-spread of the individual paper should be given before 'in' and then the title of the book and other full details. Examples are to be found in any issue of Environmental Conservation. Authors must ensure that their references are accurately cited: the Editor will be apt to refer back any which appear incorrect or incomplete, or to reject any submission in which errors are so frequent as to raise doubts regarding its general reliability.

Illustrations are welcomed in limited numbers when really vivid and meaningful. Submission of single copies will suffice if necessary but all must be identified by at least the [first] Author's surname and then figure number lightly pencilled on the back. Maps and other line drawings should be in a form ready for reproduction without redrawing, with stencilled or printed lettering and lined or large-dotted shading, and suitable for reduction either to $8.1 \mathrm{~cm}$ (single-column) or occasionally $16.5 \mathrm{~cm}$ (double-column) width. Photographs should normally be black-and-white glossy prints showing clear details and adequate contrast. If not evident from some feature of known or indicated dimensions, the scale of all illustrations should (for maps must) be indicated either by a statement in the caption or by a graduated line marked in the appropriate metric unit. Return of originals if desired should be indicated clearly but cannot be guaranteed, though a reminder when proofs are retumed should be a safeguard. Costs of coloured illustrations can be quoted by the printers, whose address is given near the end of the penultimate paragraph below and also at the foot of the back cover of each issue of the Journal.

Proofs will be sent to the Author (or the first-named alone if more than one) of each signed paper or other contribution. They will be accompanied by an addressed sticky label for speedy return to the Editor, who reserves the right to 'pass for press' if Authors' corrections are not received by the date indicated on the accompanying green slip headed 'Proof's'. A form for ordering extra offprints (see next paragraph), or reprints with no extraneous material but printed covers if desired, will be enclosed with the proofs, and, together with a cheque for the appropriate amount (made out to the Foundation for Environmental Conservation and preferably in Swiss francs or US dollars), should be returned to the Editor with the corrected proofs. In cases of plural authorship, Authors receiving proofs are asked to check with their Co-authors concerning corrections and ordering of reprints. In view of the extremely high and ever-rising costs of printing, and particularly of altering set pages, it is requested that only necessary corrections be made in proof, although, exceptionally, suggestions for alterations or brief additions may be entertained if space allows. In cases where the cost of all proof corrections etc. exceeds $5 \%$ of the cost of composition or 50 Swiss francs, Authors or their institutions are liable to be sent bills for reimbursement of the Foundation for Environmental Conservation which will have paid them.

Fifty Free Offprints will be sent to the Author (or the first-named if more than one) of each signed paper or short communication etc provided the are claimed on the Ordering Form accompanying the proofs.* This privilege does not extend to Conferences \& Meetings or Reviews \& Notices items, of which personal permission to photocopy freely is granted solely to their Authors provided due acknowledgement of the Journal is made Additional offprints, or reprints with printed covers if desired, may be ordered at the prices indicated on the Ordering Form. Questions regarding reprints (such as of unsigned items), possible loss, quotations for especially large orders or coloured illustrations, etc., should be addressed to our Printer, Mr Gilbert E. Huguet, 43 Route de Loëx, 1213 Onex/Geneva, Switzerland - not to the Editor or owning Foundation.

The Editor wishes to indicate his availability for consultation but to emphasize that the more closely the above instructions are adhered to in the preparation and submission of a manuscript, the speedier will be its consideration and, if accepted, publication. For general style it is recommended that a recent issue of the Journal be consulted.

* Savings from not sending out free offprints automatically any more are helping us to give at least one 'Best Paper' prize each year. 
Volume 18, No. 4 - Winter 1991

CONTENTS

Editorial Section: [Stressing Clean Energy]

Introduction: Background and Objectives of the World Clean Energy Conference, by President Gustav R. Grob

Main Points in Opening Address by German Federal Minister of the Environment, Nature Protection, and Nuclear Safety, by HE Professor Dr Klaus Töpfer ..

Further Statement at Opening of World Clean Energy Conference, by Professor G.O. Patrick Obasi, SecretaryGeneral of WMO

Request Statement: Energy and The Biosphere, by Nicholas Polunin

Pages

The World Energy Coalition and the Global Energy Charter, by Dr Hari N. Sharan \& President Gustav R. Grob

Updated Notice: Index of Titles and Authors published in Environmental Conservation during 1974-86, with ongoing Supplements

\section{Main Papers:}

Man-induced Global Change of Climate: The IPCC Findings and Continuing Uncertainty Regarding Preventive Action, by Professor Bert Bolin (6 figs and 2 tables)

Solar-Hydrogen Energy System: The Choice of the Future, by Professor T. Nejat Veziroglu \& Frano

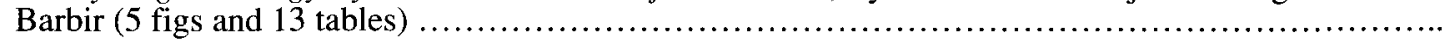

The MINK Project: A New Methodology for Identifying Regional Influences of, and Responses to, Increasing Atmospheric $\mathrm{CO}_{2}$ and Climate Change, by Dr Norman J. Rosenberg \& Dr Pierre R. Crosson (fig. and 3 tables) ....

A Methodology for Assessment of External Issues Facing National Parks, with an Application in Costa

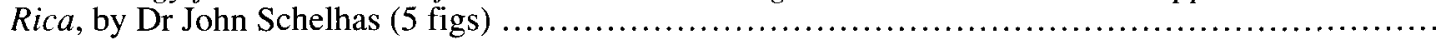

Australia's Distinctive National Parks System, by Dr Geoffrey Charles Westcott (map and 3 tables) ....... Competing for Water on the Indus Plain: Is There a Future for Pakistan's River Dolphins?, by Randall R. Reeves, Dr Abdul Aleem Chaudhry \& Umeed Khalid (3 figs and 2 tables) ..........................

The St Lawrence Beluga: A Concerted Effort to Save an Endangered Isolated Population, by Jacques Prescott (2 figs)

Short Communications \& Reports:

Substance of Keynote Address to World Clean Energy Conference, by Hermann Scheer, MP ....

Conclusions of the World Clean Energy Conference, Geneva, 4-7 November 1991, by President Gustav R. Grob.

British Nature Conservancy Council: Final Report, by Dr E. Barton Worthington ......................

Climate Scenarios for Alpine Regions: A Collaborative Effort between ICALPE and ProClim, by Dr Martin Beniston \& Martin F. Price (2 figs) .....

Vegetational Boom or Bust in Arid Australia, by Professor John L. Cloudsley-Thompson (2 figs) ...

Protected Areas and Biodiversity: How the IVth Parks Congress Will Contribute, by Jeffrey A. McNeely $364 \& 372$

Notes, News \& Comments:

Shijun Ma (1915-91), by Gaoming Jiang, Hongchang Li \& Nicholas Polunin (portrait) .....

A Tiny Paradise of Nature, by Jeanette Dür-Lindt (2 figs)

The St Sorny Nature Demonstration Reserve in Southern France, by Dr Alfred Necker \& Nicholas Polunin (fig.) ......................... Ariankavu Pass, a Lost Elephant Corridor in South
Pages India, by Dr A.J.T. Johnsingh, S. Sathyakumar \& S.F. Wesley Sunderraj (fig.) ................... 357-8 Heritage Resources Centre, by Professor J. Gordon Nelson \& Rafal Serafin ......................... The Banff Centre for Management's Recent or Impending Initiatives in Environmental Innovation, by Felicity Edwards ..................... Trees and Soil Stabilization, by John Rawnsley .... Future of the Forestry Work-force, by Dean George Brown \& Dr John J. Garland .......................

360-3 UNEP and Canon's International Photographic Competition 'Focus on Your World', by Tore $\mathbf{J}$. Brevik ........................................ 363-4 Brevik ..................

Reports by UN/ECE, John C. Payne \& Dr Susan K. Jacobson, and Dr Gunavant M. Oza; Important Prospects by Club de Bruxelles, Jeffrey A. McNeely, Dr Guido Van Steendam, Dr Roger H. Charlier, and Dr Dennis Thompson ..................

Reviews \& Notices:

Reviews by Dr Arthur H. Westing, Professor John 366-7 L. Cloudsley-Thompson, Dr Nicolai N. Smirnov, Professor Richard Evans Schultes ..................

Environmental Conservation: Contents of Volume 18,

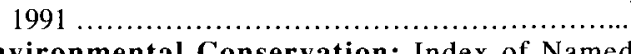

Environmental Conservation: Index of Named Contributors to Volume 18 .

(C) 1991 THE FOUNDATION FOR ENVIRONMENTAL CONSERVATION,

7 CHEMIN TAVERNEY, 1218 GRAND-SACONNEX, GENEVA, SWITZERLAND

All rights reserved. With the exception of photocopying or other reproduction with due acknowledgement of their own items only by Authors or Co-authors in the Conferences \& Meetings and Reviews \& Notices sections (of which no free offprints are given though reprints with covers can be purchased), no part of this publication may be reproduced, stored in a retrieval system, or transmitted, in any form or by any means - electronic, mechanical, photocopying, recording, or otherwise - without permission in writing from the Editor or the copyright-owning Foundation. Quotation of brief passages with due citation is, however, welcomed. 